IZA DP No. 8471

Student Scores in Public and Private Schools: Evidence from PISA 2009

Stephane Mahuteau

Kostas Mavromaras

September 2014 


\title{
Student Scores in Public and Private Schools: Evidence from PISA 2009
}

\author{
Stephane Mahuteau \\ NILS, Flinders University \\ and IZA \\ Kostas Mavromaras \\ NILS, Flinders University \\ and IZA
}
Discussion Paper No. 8471
September 2014

\author{
IZA \\ P.O. Box 7240 \\ 53072 Bonn \\ Germany \\ Phone: +49-228-3894-0 \\ Fax: +49-228-3894-180 \\ E-mail: iza@iza.org
}

\begin{abstract}
Any opinions expressed here are those of the author(s) and not those of IZA. Research published in this series may include views on policy, but the institute itself takes no institutional policy positions. The IZA research network is committed to the IZA Guiding Principles of Research Integrity.

The Institute for the Study of Labor (IZA) in Bonn is a local and virtual international research center and a place of communication between science, politics and business. IZA is an independent nonprofit organization supported by Deutsche Post Foundation. The center is associated with the University of Bonn and offers a stimulating research environment through its international network, workshops and conferences, data service, project support, research visits and doctoral program. IZA engages in (i) original and internationally competitive research in all fields of labor economics, (ii) development of policy concepts, and (iii) dissemination of research results and concepts to the interested public.
\end{abstract}

IZA Discussion Papers often represent preliminary work and are circulated to encourage discussion. Citation of such a paper should account for its provisional character. A revised version may be available directly from the author. 
IZA Discussion Paper No. 8471

September 2014

\section{ABSTRACT}

\section{Student Scores in Public and Private Schools: Evidence from PISA 2009}

This paper examines critically the presumption that, other things equal, private schooling offers higher quality education than public schooling. We apply multilevel regression on the 2009 PISA to estimate the differential effect of public and private schooling on student scores in Australia. We control for observable and unobservable influences, at school and student levels. We find that public-private schooling quality estimated differences are not statistically significant, but Catholic schools perform better than both. Differences by sector in the level of resourcing, plays a minor role. Student socioeconomic status differences and resulting selection, drive the observed better private schooling scores outcomes.

JEL Classification: $\quad$ I24, I21, I28

Keywords: $\quad$ PISA, government schools, school quality, multilevel modelling

Corresponding author:

Kostas Mavromaras

National Institute of Labour Studies

Flinders University

GPO Box 2100

Adelaide, South Australia 5001

Australia

E-mail: k.mavromaras@flinders.edu.au 


\section{Introduction and Policy Background}

It is often presumed that public schooling offers lower quality education for several reasons, including that it may be less resourced, or because the private sector may be able to manage staff in a more market-oriented manner, to the benefit of education quality. This paper examines this proposition critically for the Australian case, applying multilevel regression analysis on the 2009 PISA data. Australia has been undergoing a reform which was introduced by the 2007-2013 Labour governments, following the publication of the Gonski Review (2011) and its subsequent selective implementation. A key position of the Gonski Review was that there should be a substantial increase in school funding and that this funding increase should be offered to both sectors in a "sector blind" way. Although some of the recommendations of the Gonski proposals were altered in the process of their implementation, one of its core assumptions was retained, namely that, other things equal, the public and private schooling sectors in Australia are equally capable to convert additional funding into education quality improvements. After the 2013 elections, the policy reform that followed from the Gonski recommendations appears to have retained its pre-election bipartisan support, albeit in a qualified manner with the incoming Coalition government questioning the long-term funding needs and levels of the scheme within its broader austerity agenda. The premise of the policy reform that spending through either the public or the private schooling sector will have a similar educational effect has remained unchallenged.

Apart from the strong domestic interest in the capacity of the two sectors to deliver similar quality of education improvements, the highly integrated mix of public-private schooling provision in Australia can be of interest to the international audience. This is especially so for countries that contemplate a policy change that may entail altering the public-private sector composition of education provision at the national level. Whether the presumption of Australian policy that reform should be sector-blind is borne by the evidence or not, is one of the core policy questions addressed in this paper. The answer will be useful for policy design towards more or less private sector provision in Australia and overseas and will have implications on several counts, including the way in which dispersion of public funding for education can be justified. In the absence of efficiency differences, equity objectives would determine whether distributing public funding towards private or public schooling would be desirable. However, if there is evidence supporting an efficiency argument which suggests that either private or public provision can deliver better quality education, then any equity objectives would have to be built into that efficiency argument.

Much of the resulting debate is centred on two main ways in which education outcomes may be influenced by sector. First, debate focusses on the influence of the socio economic characteristics of 
the students in a school, principally because students of a higher socio economic status (SES) tend to self-select into private schools that are better funded through their fees, thus improving the relative performance of these schools at the expense of the remaining students in the remaining public schools. Second, debate focusses on the influence of public funding on schools, principally because it is more likely that public funds will be distributed in an equitable way, or in a way that is also concerned with equity, thus promoting the relative performance of public schools.

To understand the differential influence of SES and of school resourcing on student education performance outcomes by sector, this paper disentangles the influence of observable and unobservable factors on the variation in PISA scores, distinguishing between factors associated with individual student characteristics and factors associated with the overall characteristics of the schools that students belong to. The empirical analysis controls for the effect of SES and resourcing and presents their estimates alongside with the estimated impact on scores of a school being in the public or the private sector. The main conclusion of the paper is that the PISA data supports a key element of the Gonski proposed reform, namely that policy should be sector-blind in the way it dispenses of the recommended additional funding. Results suggest that, although there is a modest impact of resources on scores after all other observable factors have been taken into account, the prime impact on scores comes from the non-random self-selection of high SES students into private schools that charge fees. It is the indirect impact of SES that drives the higher observed scores of the average private school against the lower observed scores of the average public school, and not any intrinsic higher quality in education provision by the private school sector.

\section{Data and methodology}

\subsection{The Data}

The Programme for International Student Assessment (PISA) is an international survey undertaken every 3 years by the OECD across 67 countries. The PISA aims to test and record the skills and knowledge of 15 year old high school students. We use the 2009 Australian component of the PISA survey, which distinguishes between public and private sector schools. We restrict the data to the Australian survey since country specific datasets are richer than the equivalised data available for all participating OECD countries. Notably, important variables for the Australian school system related to remoteness and indigenous status are not in the broad OECD data but can be obtained for the Australian data. The advantage of the PISA survey as an information source for this paper is the double sampling nature of the data it collects. A number of schools are sampled (around 350 in Australia in 2009), from which a sample of students is drawn (around 14,500 students in Australia in 2009). As a result, both characteristics of students and schools (as given by the school principal) are available. This gives the PISA data a hierarchical structure, comprising students at the first and more 
detailed level, who are nested in schools at the second and broader level. Having reliable and complete information for both levels enables us to decompose student scores variation into (i) the variation between all student scores within each school (within school variation) and (ii) the variation between all average scores of students in different schools (between schools variation).

The hierarchical structure of the data allows us to control for the degree to which observed and unobserved heterogeneity arising from school overall differences, may influence individual student scores. The underlying idea is that students who belong to the same school will influence and be influenced by a number of shared school characteristics, which are either observed (e.g. socio economic status, location and other), or unobserved in the data (e.g. school learning environment, the involvement and ability of teachers, the level of school discipline and other). Our use of a multilevel hierarchical regression model explicitly accounts for the multilevel structure of the data by distinguishing between the school effects and the student effects on scores (see Rabe-Hesketh \& Skondral, 2008). The results presented in this paper are generated following two steps. In the first step we estimate the determinants of student PISA scores, using a multilevel hierarchical model specification. In the second step, we combine the estimates of the multilevel model with appropriate decomposition methods to derive a number of pertinent counterfactual scenarios of interest for different combinations of student and school types.

\subsection{Estimation Methodology}

The PISA scores of students depend on a vector of student, family background, school and environmental characteristics. We take into account the hierarchical nature of the data through the definition of variance components as follows:

$P_{i j}=X_{i j S} \beta_{S}+Z_{j S} \gamma_{S}+u_{j S}+\varepsilon_{i j S}$

Where $X_{i j s}$ are the individual characteristics of person $i$ in school $j, Z_{j s}$ are the characteristics of school $j$ shared by all students attending this school. Crucially, the use of the hierarchical model structure allow us to estimate $u_{j s}$ as a random intercept associated with the school $j$ student $i$ attends. We use the maximum likelihood method (Rabe-Hesketh \& Skondral, 2008) to compute the school specific component $u_{j s}$ which gives an estimate of the systematic effect of belonging to school $j$ on scores, over and above the effect of observed school resources. The estimate of the random intercept $u_{j s}$ is commonly used as an indicator of school quality in the literature that looks at student outcomes based on an educational production function (Heck, 2000; Meyer, 1997; Hanushek \& Rivkin, 2010). This paper compares the distribution of the estimated 'school quality' for each school type and tests whether the whole distributions of estimated quality are statistically different by school type. 
Vector $X$ in Equation 1 contains student characteristics which are identified in the education literature as being closely related to student performance (Hanushek, 2005; Woesmann, 2008; Goldstein, 2004; Fertig \& Schmidt, 2002). We add variables associated with student disadvantage in terms of education resources available at home. We also add information available in the PISA 2009 data on parental socio economic status. Parental socioeconomic status (denoted ESCS) is captured by the composite index available in the PISA data (see OECD, 2007) which is obtained by principal component analysis and crosses five dimensions of the background of students (captured by parental information on highest occupation, education, family wealth, cultural possessions and home educational resources). The ESCS index has been computed to allow over time as well as cross country comparisons and has been standardised so that the mean ESCS of all OECD countries is 0. Australian students surveyed in PISA 2009 have a population weighted mean ESCS of 0.344 (at the school level, the individual mean ESCS is 0.315) reflecting the fact that the Australian mean socioeconomic status is above the OECD average. Alongside with ESCS, we include information on indigenous status and migrant status of the parents and the students, and measures of the relative remoteness of their place of residence. Vector $Z$ represents school characteristics shared by all students in the school, summarizing the school environment both in terms of resources and socio economic mix of the student body. Central to this paper is the distinction of school type between government, independent and catholic.

We follow the way the PISA survey tests students and presents scores on three subjects (Reading, Maths and Science) and we carry out and present three sets of estimations for Equation 1, one for each of the three reported scores of Reading, Maths and Science. We use the estimation results of Equation 1 to perform counterfactual analysis which focusses on the effect of school type on expected student scores. Our broadly interest is to examine the differences in scores between Catholic, Independent and Government schools. Counterfactual analysis allows us to account for the fact that students attending Catholic or independent schools will have different characteristics, and provide a (counterfactual) estimate of what the score of an average Government school student would be if she attended respectively a Catholic school or an average Independent school. We use decomposition techniques, which allow us to generalise results to all students in all school types.

We complete our analysis by utilising the information provided by the estimated random intercept for each school (which we remind the reader is interpreted as an estimate of 'school quality', over and above observable resources and the student body mix) in order to compare score outcomes following the estimated distributions of school quality by school type. 


\section{Estimation Results}

\subsection{Overview of results presentation}

This section presents estimation results on scores, identifying both student and school effects via the multilevel specification described in the methodology section. We present and discuss the results obtained using the multilevel specification, especially the random intercept which accounts for unobservable school effects on scores. The introduction in the specification of variables representing observed school and student characteristics reduces the variability of scores, especially the score variability between schools.

We first note that of the total variance in scores, 75 per cent can be attributed to between students differences and 25 per cent can be attributed to between schools differences (see Table A1 variance partition coefficient). We then note that after we have controlled for all observed between schools differences (see Table A2, variance partition coefficient) we still find that 6-7 per cent between schools variance in scores remains. This gives us a measure of the relative size of the unobservable variation in scores which is used to compute the residual school effects, which we interpret as a measure of 'school quality'. Our results show that estimated unobservable 'school quality' leads to significant differences in scores between identical students attending schools that have otherwise identical observable characteristics.

We use the estimated measure of 'school quality' to calculate the scores of given types of students when they are placed in a (counterfactual) school which belongs to another sector than their own (actual) school's sector. We estimate separately scores on Reading, Maths and Science and estimation results are found in Table A2.

\subsection{The effect of School SES and Student SES}

One of the most important relationships in the context of schools and education outcomes is the strong and positive association between the socioeconomic status (SES) of a student and their PISA scores. The SES is associated with scores at both the individual level and at the overall school level represented by the mean score of all school students. The following table is an extract of Table A2 estimation containing only the relevant socio economic status variables.

\begin{tabular}{lccc}
\hline Variables & Reading & Math & Science \\
\hline Student ESCS (pop mean: 0.3439) & $\mathbf{9 . 5 2 * * *}$ & $\mathbf{1 1 . 5 * * *}$ & $\mathbf{1 1 . 3 * * *}$ \\
& $(1.44)$ & $(1.36)$ & $(1.49)$ \\
School average ESCS (school mean: 0.315) & $\mathbf{6 9 . 8 * * *}$ & $\mathbf{7 2 . 2 * * *}$ & $\mathbf{7 8 . 9 * * *}$ \\
& $(13.3)$ & $(13.7)$ & $(15.2)$ \\
Male interacted with School ESCS & $\mathbf{6 . 3 6}$ & $\mathbf{- 0 . 7 2}$ & $\mathbf{2 . 2 7}$ \\
& $(3.91)$ & $(3.73)$ & $(4.09)$ \\
\hline \multicolumn{2}{c}{ Standard errors in parentheses ${ }^{* * *} p<0.01,{ }^{* *} p<0.05,{ }^{*} p<0.1$} &
\end{tabular}


Table 1 presents the estimates obtained on the association between ESCS and student scores, found to be positive and significant at both the individual student and the school level. ${ }^{1}$ Results in Table 1 indicate that after everything else has been held constant, the socio economic mix of students composing the school is strongly associated with student scores. An individual student from a higher socio economic status is more likely to achieve higher scores, irrespective of the school they attend. Put simply, a student with a socio economic background above the population mean can be expected to have a higher score than fellow students of the same school but with a lower socio economic background. For reading scores, we estimate this difference to be about 9.5 score points higher for every point above the population mean of ESCS. The same difference is about 11 score points higher for maths and science. We also tested an alternative specification of the model by adding a random coefficient to the measure of ESCS. The purpose of this specification was to test whether the effect of ESCS (as measured by its slope coefficient) was significantly different depending on which schools students attend. The expectation was that ESCS may be associated with scores in a different manner depending on the sector of the schools. Our random coefficients specification turned out to provide poorer estimates than the simpler random intercept specification, suggesting that the association between ESCS and score does not significantly vary in a systematic fashion across all schools to warrant any further investigation by school sector.

Table 1 highlights the strength of the association between school average ESCS and scores. It suggests that most of the observed score differences between government and private schools stems from the underlying inequality in the ESCS distribution by school sector. We note that the mean of the population weighted ESCS index in Government schools is 0.12 , which is much lower than 0.46 in Catholic and 0.73 in Independent schools. The relative strength (by school sector) in the association between the ESCS and scores is a result found by a number of studies, notably by Cardak \& Vecci (2013) who find that in Australia the higher literacy scores observed in Catholic schools are mainly due to a selection bias attributable to both observed characteristics (mainly SES) and unobserved characteristics (related, for instance, to stricter discipline in Catholic schools). The result that the SES composition at the school level explains most of the score differences between government schools and private schools is also found by Lubienski \& Lubienski (2013), who show that, once the composition effect of the student body is taken into account, government schools in the US outperform private schools.

\footnotetext{
${ }^{1}$ Note that the large estimate for School ESCS is in part due to the wide range of the ESCS index.
} 


\subsection{School level variables and estimated random intercepts}

This section builds on the distinction between the two main categories of school level variation. First we investigate the observed school level variation, represented by several observable school level characteristics such as location, resources (IT, student-teacher ratio), organisation (support for ESL students), and sector.

Second, we investigate the residual (unobserved) "between schools" variation which the paper interprets as a measure of the differences in school quality. We present the distribution of school quality using caterpillar plots which offer a good visual understanding of the whole distribution and can also include their estimated confidence intervals.

\section{Observed school level variation}

It appears that after we control for school and student characteristics, the scores are not affected by whether the school is in a remote area or in a city. Schools in provincial areas obtain significantly better scores than city schools in maths and science, everything else held constant. No differences in reading scores were detected. This is an important result. It suggests that the overall lower scores achieved by students in non-metropolitan schools arise from the characteristics of the students (background) and from the school resources available to them, but not from their geographical situation per se.

We observe a positive association between reading and maths scores and the number of computers available for study purposes at school. Interestingly, this association is not found for science scores.

Students enrolled in independent schools have significantly lower scores in all subjects than their government schools counterparts. Students who attend Catholic schools have significantly lower scores in maths and science. This result shows that the observed superior average performances of students in non-government schools should be attributed to factors such as the higher ESCS of the student body, more resources per student, more parental support and/or pressure, and less absenteeism among students, rather than to some intrinsic quality difference between school sectors. This result corroborates a number of contributions found in the literature, notably Ryan (2013) who investigates the causes of the decline in PISA scores in Australia between 2000 and 2009. He finds that while there was a significantly positive score differential between private schools (Catholic and Independent) and public schools in 2003, it had all but vanished by 2009.

Our estimations do not reveal any association between scores and student to teacher ratio. This finding could be the result of tightly regulated class sizes and related classroom supports in Australia 
not allowing for large differences to arise. This finding is consistent with similar findings in the literature based on evidence from Australia and other countries (see notably Dearden et al. 2002), including other data sources such as the Australian NAPLAN.

\section{Residual between-school variation: 'school unobserved quality'}

Looking at the original model (Table A1, depicting a proportion of total variance of 25 per cent to be due to between school variability) we note that between 5.5 per cent (for reading) and 7.3 per cent (for science) of the total variation in scores is explained by the unobserved heterogeneity that can be attributed to schools after controlling for student and school effects. Simply put, this is what is left of the between-schools variance, after we have controlled for such things as school average ESCS, teacher/student ratio, school type, geographical location, state and more. The intuition that comes out of this finding is that the part of school quality that is hard to quantify and measure in the data, has much less of an independent effect on student outcomes than we may sometimes be asked to believe.

We use the estimations results to estimate the expected value of each school's random intercept along with the 95 per cent confidence interval around this estimate. The value of the random intercept for a school can be interpreted as a measure of the extent to which the mean scores of the school may differ from the overall mean scores of all schools. For example, the finding that a specific school has a random intercept significantly below the overall mean, means that students in this school perform significantly worse than the average school, over and above all controls used in the model. Figures A1 to A3 in the Appendix give an illustration of the estimated school effects for each subject tested. While the between schools variation has been reduced considerably after controlling for students and school observable characteristics, the score differences between the lowest and highest achieving schools (what we have called the school 'quality') are statistically significant from one another. For instance, for reading scores (Figure A1), the lowest achieving schools are associated with gaps amounting to up to 40 points compared to the overall average, while the highest achieving schools outperform the overall average by up to 60 points. In other words, there still remains a gap of 100 points between highest and lowest achieving schools that is not due to the characteristics we included in the model. Note that most schools lie between plus or minus 20 points from the mean. It is the remaining differences between schools that we interpreted as differences in 'school quality'. They represent the estimated systematic deviation from the overall mean score after schools have been made comparable by controlling for their own characteristics and for the individual characteristics of their students. 


\subsection{Counterfactual analysis by school sector}

We use counterfactual analysis to investigate the extent to which the score outcomes by sector are due to the observed and unobserved characteristics of the students and the schools in each sector. We ask simple but important questions, like "what would be the scores of the present student body that presently attend an Independent school, if they were to attend a Government or a Catholic school?”2

We examine the association between school sector and student scores, to trace the differences in scores between Catholic, Government and Independent schools. Since students attending Catholic or Independent schools have different characteristics, counterfactual analysis is used to calculate the score of an average Government school student if she attended respectively an average Catholic or Independent school. Since the average characteristics of the schools differ by sector, we also ask what would be the expected scores for an average Catholic school student (and average Independent school student) if she were to attend an average Government school. Thus, counterfactual analysis allows us to make a judgement about the relative contribution of different factors that are associated with scores. Crucially for this paper, counterfactual analysis allows us to distinguish between the relative influence of schools and students characteristics on scores, in the context of Government, Catholic and Independent schools.

\section{Government, Catholic and independent schools and their students: counterfactual analysis}

We use the characteristics of students and schools to estimate predicted scores following several scenarios. First we assume a student with characteristics corresponding to the population average of Government school students (we use population weighted means) attending a school with the Government school population average characteristics. Let us denote this type of student a 'Government school student' attending a 'Government school'. Likewise we can define a 'Catholic school student', attending a 'Catholic school', and an 'Independent school student' attending an 'Independent school'.

\footnotetext{
${ }^{2}$ Counterfactual analysis is a simple form of multivariate decomposition which allows us to ask several pertinent questions using the estimation results of the paper. As a post-estimation calculation, it is highly dependent on the statistical robustness of the underlying model. Our model has produced both sensible and statistically significant results. The method works down to individual variable and coefficient level. It is clear that there are many interesting such calculations that can be made and that the intuition we gain will depend on the choice of the question we ask and can only be as good as the underlying model that supports it.
} 
Table 2: School types and Student types, counterfactual analysis on observed characteristics

\begin{tabular}{|c|c|c|c|c|}
\hline Reading Scores & & & & \\
\hline Student & Government & Catholic & Independent & Non-Government \\
\hline Government & 503.7 & 521.0 & 527.5 & 524.7 \\
\hline Catholic & 516.7 & 534.0 & 540.5 & - \\
\hline Independent & 531.4 & 548.7 & 555.2 & - \\
\hline Non-Government (Cath. \& Ind.) & 523.3 & - & - & 544.4 \\
\hline Math Scores & & & & \\
\hline Student & Government & Catholic & Independent & Non-Government \\
\hline Government & 505.0 & 516.1 & 524.4 & 520.9 \\
\hline Catholic & 516.8 & 527.9 & 536.2 & - \\
\hline Independent & 530.9 & 542.0 & 550.4 & - \\
\hline Non-Government (Cath. \& Ind.) & 523.1 & - & - & 539.1 \\
\hline Science Scores & & & & \\
\hline Student & Government & Catholic & Independent & Non-Government \\
\hline Government & 517.4 & 531.0 & 539.2 & 535.8 \\
\hline Catholic & 530.1 & 543.7 & 552.0 & - \\
\hline Independent & 545.4 & 559.0 & 567.3 & - \\
\hline Non-Government (Cath. \& Ind.) & 537.0 & - & - & 555.5 \\
\hline
\end{tabular}

Our scenarios mix the three types of students with the three types of schools in Table 2 to produce the full complement of actual and counterfactual scores, providing one full set of results for each of the three scores of Reading, Maths, and Science. Given that the number of Independent and Catholic schools in the sample is much lower than the number of Government schools (63 in PISA 2009, against 73 Catholic schools and 217 Government schools), we also performed the counterfactual analysis splitting the sample only between government and non-government schools.

The numbers in bold in Table 2 correspond to the 'actual' scenarios. The first row of Table 2 refers to Reading scores and reads as follows. The score of 503.7 presents the actual score for an average Government school student attending a Government school. The next score of 521.0 in the first row estimates the counterfactual (predicted) score of an average Government school student attending an average Catholic school. The third score of 527.5 in the first row estimates the counterfactual score of an average Government school student attending an average Independent school. The last score of 524.7 in the first row estimates the counterfactual score of an average Government school student attending an average non-Government school and is, in essence, a weighted average of the Catholic and Independent schools counterfactuals. The remaining rows of Table 2 can be interpreted according to the description of the first row.

The comparison between Catholic and Government schools, suggests that the average Catholic school student in a Catholic school obtains a Reading score that is about 6 per cent higher than the score 
obtained by the average Government school student in a Government school (534 against 503.7). For Maths and Science scores, the gap is respectively 4.5 per cent and 5 per cent. Considering the average Government school student attending the average Catholic school, her Reading score would improve from 503.7 to 521, that is an improvement of 3.4 per cent, the Maths score by 2.2 per cent (505 to 516.1 ) and the Science score by 2.6 per cent (517.4 to 531). Interestingly, the opposite counterfactual scores for the average Catholic school student attending the average Government school yields an almost identical score prediction (in absolute value). Indeed while the Government school student placed in a Catholic school would improve her Reading score by 3.4 per cent, the average Catholic student placed in a Government school would experience a drop in Reading score of 3.2 per cent. Likewise, Catholic school students placed in a Government school would see their Maths and Science scores drop by respectively 2.1 and 2.5 per cent. We obtain very similar results on a different scale when comparing Government and Independent schools and students. These figures indicate the score improvements to be expected for Government school students who attend a Catholic or an Independent school. For Reading scores they show that out of the 30 points difference between Government school students in Government schools and Catholic school students in Catholic schools, about 60 per cent can be attributed to differences in school observable characteristics which are mainly driven by variables associated with resources and average ESCS of the school. The symmetry of this result is interesting to point out where Catholic students would experience the same percentage drop in Reading score should they be attending the average Government schools. Finally these results can be generalised to comparisons between Government and Independent schools and are stable whether one looks at reading scores or math or science.

\section{Comparing Government, Catholic and Independent schools estimated 'quality'}

As we have pointed out in the beginning of the estimation results section, an important source of variation in student scores can be attributed to the unobservable characteristics at school level, which we interpret as 'school quality'. After we take into account all observable characteristics, a residual between 6 and 7 per cent of the total variability in student scores can be attributed to 'school quality'. This is a sufficiently large percentage and warrants further investigation. To this purpose we examine the distribution of 'school quality' by school sector. Figures 1, 2, and 3 show the estimated quality by sector (Independent and Catholic in the left and Government in the right panel) and by type of score (Reading, Maths and Science). For each subject, we plotted the distribution for government schools separately since there are a lot more of these schools compared to Catholic and Independent schools and Catholic and Independent schools are very similar in their quality distributions. 

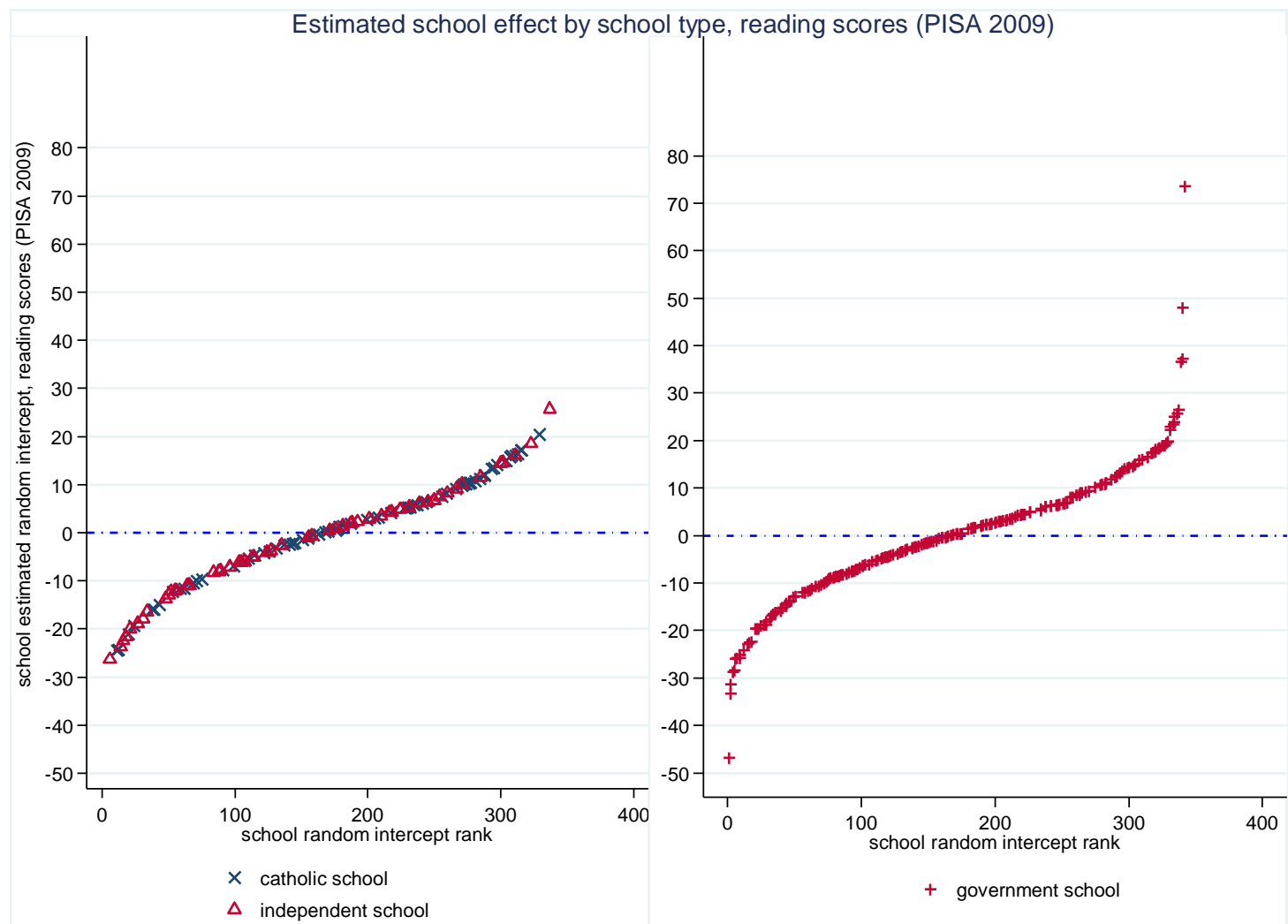

Figure 1: Estimated school effect by school type, Reading scores (PISA 2009)

Estimated school effect by school type, math scores (PISA 2009)
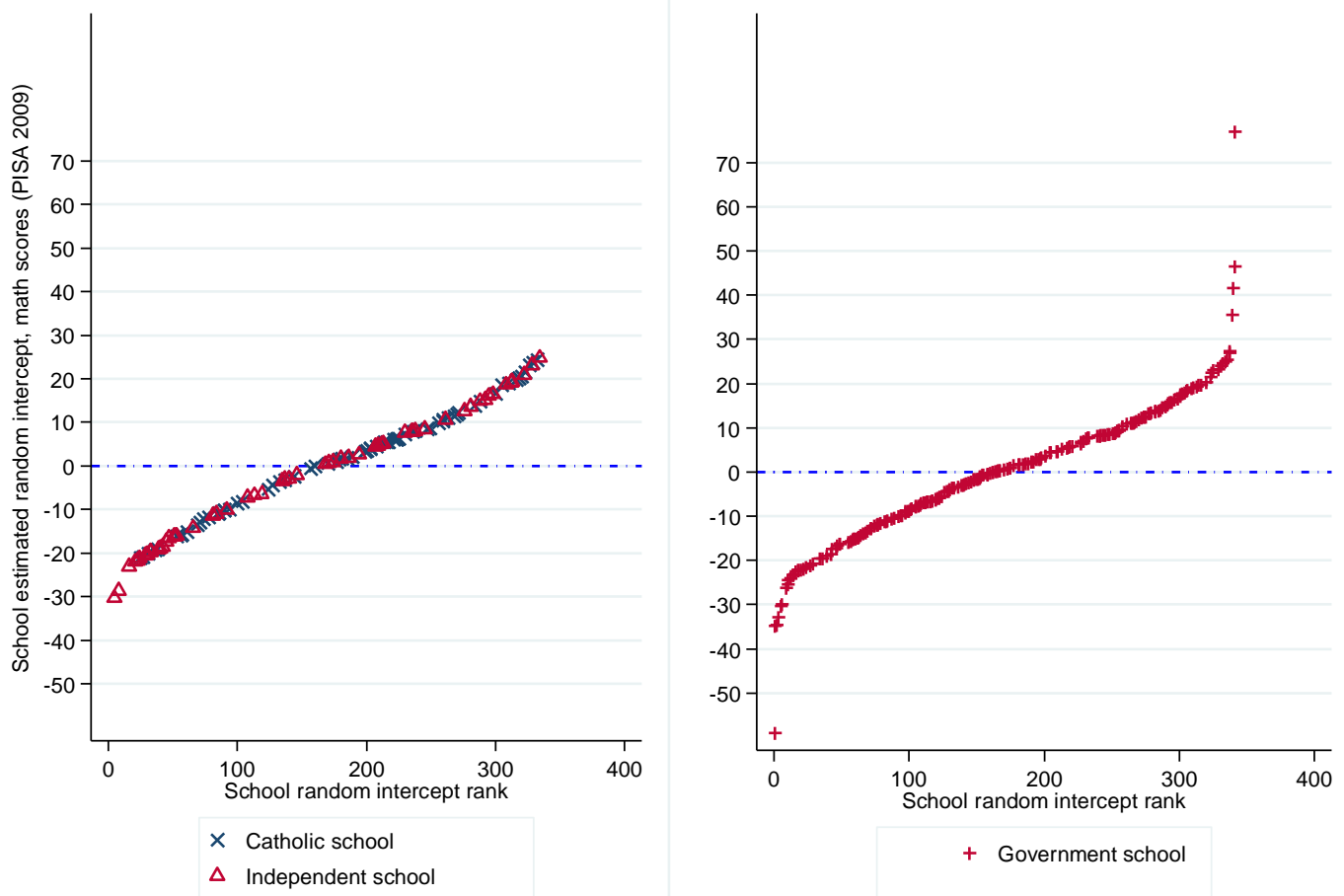

+ Government school

Figure 2: Estimated school effect by school type, Math scores (PISA 2009) 


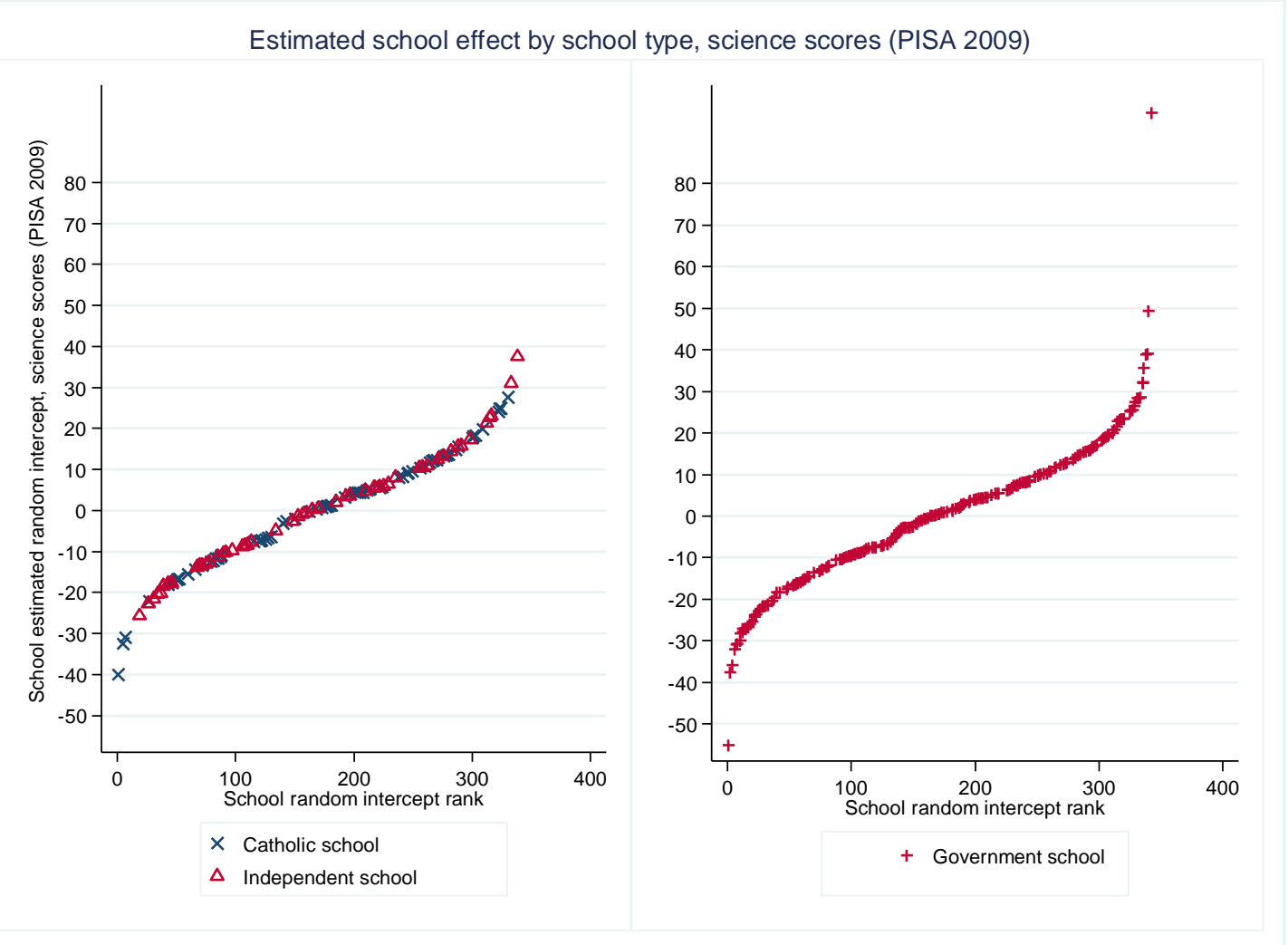

Figure 3: Estimated school effect by school type, Science scores (PISA 2009)

Figures 1 to 3 suggest that for all three subjects, the distributions of the quality of Catholic and Independent schools show a smaller amplitude in both their negative and positive sides. In all subjects, Government schools exhibit a more pronounced negative deviation tail than nonGovernment schools, suggesting that cases of extreme low quality are more likely to be found among Government schools. Yet, Government schools also exhibit a more pronounced positive deviation tail than non-Government schools. The suggestion is that cases of extreme high quality are also more likely to be found among Government schools. We performed a series of Kolmogorov-Smirnov tests in order to statistically compare these distributions across school sectors for all subjects. We first tested whether 'school quality' was significantly smaller or larger for Government schools against non-Government schools (that is Catholic and Independent schools taken as a single category). We find that Government and non-Government schools distribution of the estimated unobservable school effects are not significantly different for any of the three subjects (Reading, Math and Science). This is a simple but powerful result, which suggests that when we compare the quality distributions between Government and non-Government schools, we cannot find any statistically significant difference. Similar tests, comparing the estimated quality of Catholic with Government, Catholic with Independent and Independent with Government schools were carried out. These tests could add valuable detail, but should be read with caution because of the small sample sizes when we split the non-Government schools sample into its Catholic and Independent constituents. It appears that for Reading and for Science scores, the estimated school quality does not significantly differ between 
Government, and each of the Catholic and Independent schools. It is only for Maths scores that we find differences by sector. Catholic schools are found to perform better than Government schools and better than Independent schools. At the same time Government schools are found to perform better than Independent schools. The Maths tests suggest that when the combined positions of Catholic and Independent schools are compared with Government schools the better performance of Catholic counterbalances the worse performance of the Independent schools.

Further analysis of the shape of the distributions of estimated school quality (by comparing their third and fourth moments) shows that the distribution of Government schools quality is slightly positively skewed compared to non-Government schools but also has larger kurtosis (fatter tails) which seems to imply that while the distributions of school 'quality' per se are not significantly different (with the exception of Maths scores), Government schools could potentially exhibit slightly higher quality (for Reading scores) but more quality variability. We suspect that part of this result is due to the fact that a number of Government schools of the sample are highly selective (based on student quality) and that this selection may be responsible for the slight skewness of the distribution. ${ }^{3}$

\section{Conclusion}

This paper set out to investigate the degree to which school quality differs by sector and how estimated quality can be shown to be influenced by the socioeconomic status of students individually, as well as the socio economic status of the whole student body within a school, and by the different level and type of financial and other resources available to each school. We used the PISA data from 2009 which is a very rich source of detailed information on scores in Reading, Maths and Science and records the sector of each school. We estimated a hierarchical multilevel model which distinguishes between variation at the individual and at the school level, and which allows us to estimate individual school quality. We used the conventional education literature definition of school quality as the variation in student score outcomes that is explained neither by the observed student and school level variation nor by the unobserved individual student variation. More specifically, school quality was measured by the estimated random intercept for each school.

The core result of the paper is that school quality does not depend directly on the sector of the school. With the possible exception of Catholic schools doing better than both government and independent schools in the subject of Maths, sector does not seem to be associated with score differences. After controlling for all observed school differences between schools, the resourcing available at school level does not appear to have a strong relationship with the average scores achieved within these

\footnotetext{
${ }^{3}$ While interesting, this result must be interpreted with caution as the number of Catholic and Independent schools is relatively small and the statistics used are less precise with small samples.
} 
schools, with possible exception IT facilities which enhanced scores. The data strongly supports the simple proposition that the main determinant of higher scores in non-Government schools is the higher socio economic status of the students that choose to go to non-Government schools.

The first intuition from putting the paper's results together is that what seems to be driving the (raw data) observation that non-Government schools achieve higher scores than Government ones, is not the result of an inherent higher quality of non-Government schools. It is rather the result of the more privileged high socio economic status students self-selecting into non-Government schools and taking their existing advantage with them to these schools. This paper does not find any evidence that nonGovernment schools show any capacity to utilise the funds at their disposal more efficiently than their Government school counterparts.

Our results also provide some novel granularity to the understanding of school quality estimates. By testing the higher moments of the estimated distributions of school quality (i.e. the distribution of the random intercepts) by school type (i.e. Catholic, Independent and Government) and for each type of subject scores reported by the PISA (i.e. Reading, Maths and Science) we find great diversity, with some of the differences found to be statistically significant. The core intuition from this result is that, while on average Government and Independent schools appear to be indistinguishable, the shape of their distributions suggest that the better (worse) Government schools are more likely to be doing much better (worse) than the average Government school, than the corresponding better (worse) nonGovernment schools are doing than the average non-Government school. It appears that the choice of a non-Government school is less risky in both directions that risk can run. Investigation of the differences in the precise shape of these estimated distributions suggested that there are further differences to be found. Similarly our results suggested that Catholic schools are doing better than the rest, especially in Maths, but their smaller sample size implies that testing such hypotheses is less precise than we would desire it to be for establishing definitive conclusions.

The proposition that Government schools may be doing as well as non-Government schools has received much attention in the Australian and international literature alike. Our paper provides evidence that even after we subject some of the best data available to probably the most sophisticated methodological testing available, we can still find no evidence that the non-Government sector puts funding to a more efficient use than the Government sector. Our paper suggests that the Australian policy for a sector-blind distribution of school funding is supported by the evidence and that the main arguments for the use of public funding to support school education should be on equity grounds alone, as the efficiency of the two sectors is shown to be indistinguishable. 


\section{Appendices:}

Table A1: Random intercept estimation of reading, math and science scores, restricted model with constant only

\begin{tabular}{lrrr}
\hline VARIABLES & Reading & \multicolumn{1}{c}{ Maths } & \multicolumn{1}{c}{ Science } \\
\hline Constant & $\mathbf{5 0 8 . 9 7 * * *}$ & $\mathbf{5 0 7 . 0 1 * * *}$ & $\mathbf{5 2 1 . 9 9 * * *}$ \\
& $(3.89)$ & $(3.55)$ & $(3.72)$ \\
Variance level 2 (school) & $\mathbf{2 4 3 6 . 4 9 * * *}$ & $\mathbf{2 2 0 5 . 2 2 * * *}$ & $\mathbf{2 4 7 2 . 5 6 * * *}$ \\
& $(-346.09)$ & $(-289.91)$ & $(-363.93)$ \\
\hline Variance level1 (student) & $\mathbf{7 1 5 0 . 0 4 * * *}$ & $\mathbf{5 8 9 3 . 2 9 * * *}$ & $\mathbf{7 2 6 3 . 3 0 * * *}$ \\
& $(-149.19)$ & $(-114.19)$ & $(-147.34)$ \\
\hline Observations & 14251 & 14251 & 14251 \\
\hline No of Schools & 353 & 353 & 353 \\
Variance partition coefficient & $\mathbf{0 . 2 5 4}$ & $\mathbf{0 . 2 7 2}$ & $\mathbf{0 . 2 5 4}$ \\
\hline Standard errors in parentheses ${ }^{* * *} p<0.01,{ }^{* *} p<0.05,{ }^{*} p<0.1$ & & &
\end{tabular}


Table A2: Estimations results PISA scores, (PISA 2009)

\begin{tabular}{|c|c|c|c|}
\hline VARIABLES & Reading & Maths & Science \\
\hline \multirow{2}{*}{ Age (pop mean: 15.76) } & $19.2 * * *$ & $19.6^{* * *}$ & $19.5^{* * *}$ \\
\hline & $(2.42)$ & $(2.29)$ & $(2.50)$ \\
\hline \multirow[t]{2}{*}{ Male } & $-24.0^{* * *}$ & $20.9 * * *$ & $13.9 * * *$ \\
\hline & $(1.97)$ & $(1.86)$ & $(2.04)$ \\
\hline \multirow[t]{2}{*}{ Indigenous } & $-23.3^{* * *}$ & $-19.2^{* * *}$ & $-24.9 * * *$ \\
\hline & $(3.01)$ & $(2.85)$ & $(3.12)$ \\
\hline \multirow[t]{2}{*}{ Did not attend ISCED 0} & $-15.0^{* * *}$ & $-21.3^{* * *}$ & $-16.2^{* * *}$ \\
\hline & (3.87) & $(3.66)$ & $(4.01)$ \\
\hline \multirow[t]{2}{*}{ Attended more than 1 year of ISCED 0} & 2.02 & $-5.10 * * *$ & -0.14 \\
\hline & (1.45) & (1.38) & (1.51) \\
\hline \multirow[t]{2}{*}{ Mother did not complete year 12} & $-5.65^{* * *}$ & $-3.91 * * *$ & $-6.18 * * *$ \\
\hline & $(1.61)$ & $(1.52)$ & $(1.66)$ \\
\hline \multirow[t]{2}{*}{ Father did not complete year 12} & $-5.65^{* * *}$ & $-5.74 * * *$ & $-5.23 * * *$ \\
\hline & $(1.62)$ & $(1.53)$ & $(1.67)$ \\
\hline \multirow[t]{2}{*}{ Mother works part time (reference: FT) } & $8.66 * * *$ & $12.3^{* * *}$ & $7.23 * * *$ \\
\hline & $(1.70)$ & $(1.60)$ & $(1.76)$ \\
\hline \multirow[t]{2}{*}{ Mother is unemployed (reference: FT) } & $-7.20^{*}$ & -3.04 & -6.14 \\
\hline & (4.03) & (3.81) & (4.17) \\
\hline \multirow[t]{2}{*}{ Mother not in the labour force (reference: FT) } & 1.55 & $3.61 * *$ & $6.05 * * *$ \\
\hline & (1.91) & (1.80) & (1.97) \\
\hline \multirow{2}{*}{ Father works part time (reference: FT) } & -1.69 & -0.29 & 4.54 \\
\hline & (2.85) & (2.70) & (2.95) \\
\hline \multirow[t]{2}{*}{ Father unemployed (reference: FT) } & -0.10 & -5.36 & $-8.26^{*}$ \\
\hline & (4.13) & (3.90) & (4.27) \\
\hline \multirow{2}{*}{ Father not in the labour force (reference: FT) } & 2.16 & 1.93 & 1.87 \\
\hline & $(2.99)$ & (2.83) & (3.10) \\
\hline \multirow[t]{2}{*}{ Father is a Blue Collar Worker } & $-4.66 * * *$ & $-3.29 * *$ & $-4.29 * *$ \\
\hline & $(1.67)$ & $(1.58)$ & $(1.73)$ \\
\hline \multirow[t]{2}{*}{ Mother is a Blue Collar Worker } & $-5.49 * *$ & -1.03 & $-4.52 *$ \\
\hline & $(2.57)$ & (2.43) & (2.66) \\
\hline \multirow[t]{2}{*}{ Student was not born in Australia } & $-8.03^{* * *}$ & $-11.7^{* * *}$ & $-8.24 * * *$ \\
\hline & $(2.71)$ & $(2.57)$ & $(2.81)$ \\
\hline \multirow[t]{2}{*}{ Mother was not born in Australia } & $5.32 * * *$ & $5.27^{* * *}$ & 2.25 \\
\hline & $(1.93)$ & $(1.83)$ & (2.00) \\
\hline \multirow[t]{2}{*}{ Father was not born in Australia } & 1.82 & 0.40 & -1.60 \\
\hline & (1.91) & (1.81) & (1.98) \\
\hline \multirow{2}{*}{$\begin{array}{l}\text { Student speaks a language other than English at } \\
\text { home }\end{array}$} & $-21.7^{* * *}$ & -0.029 & $-19.6^{* * *}$ \\
\hline & (3.00) & (2.84) & (3.11) \\
\hline Single parent family (reference: nuclear family) & 0.65 & -1.01 & -2.71 \\
\hline & $(1.96)$ & $(1.85)$ & $(2.03)$ \\
\hline Mixed family (reference: nuclear family) & $-22.0 * * *$ & $-16.1^{* * *}$ & $-26.9 * * *$ \\
\hline & $(6.31)$ & $(5.97)$ & (6.53) \\
\hline Student does not have a desk & $-7.86 * * *$ & $-11.7^{* * *}$ & $-6.87 * *$ \\
\hline & $(2.93)$ & $(2.77)$ & $(3.03)$ \\
\hline books0_25 (reference: more than 100 books) & $-32.7^{* * *}$ & $-36.4^{* * *}$ & $-35.0 * * *$ \\
\hline & $(2.20)$ & $(2.08)$ & $(2.28)$ \\
\hline books26_100 (reference: more than 100 books) & $-15.3^{* * *}$ & $-18.4^{* * *}$ & $-17.2^{* * *}$ \\
\hline & $(1.68)$ & (1.59) & $(1.74)$ \\
\hline No quiet place to study & $-6.49 * * *$ & $-6.72 * * *$ & $-6.73^{* * *}$ \\
\hline & $(2.43)$ & $(2.30)$ & $(2.51)$ \\
\hline No internet at home & $-16.3^{* * *}$ & $-16.1^{* * *}$ & $-14.0^{* * *}$ \\
\hline & (3.68) & (3.49) & $(3.81)$ \\
\hline Do not read for enjoyment & $-61.7^{* * *}$ & $-38.2^{* * *}$ & $-57.3^{* * *}$ \\
\hline & $(1.81)$ & $(1.71)$ & $(1.87)$ \\
\hline Read 30 minutes or less for enjoyment per day & $-26.7^{* * *}$ & $-14.6^{* * *}$ & $-25.0 * * *$ \\
\hline
\end{tabular}




\begin{tabular}{|c|c|c|c|}
\hline & (1.73) & (1.63) & (1.79) \\
\hline \multirow[t]{2}{*}{$\begin{array}{l}\text { Minutes of class time reading per week } \\
\text { (pop mean: 237.26) }\end{array}$} & $-0.098 * * *$ & $-0.11 * * *$ & $-0.10^{* * *}$ \\
\hline & $(0.015)$ & $(0.014)$ & $(0.016)$ \\
\hline \multirow[t]{2}{*}{$\begin{array}{l}\text { Minutes of class time maths per week } \\
\text { (pop mean: 240.04) }\end{array}$} & $0.063^{* * *}$ & $0.067 * * *$ & $0.063^{* * *}$ \\
\hline & $(0.014)$ & $(0.013)$ & $(0.014)$ \\
\hline \multirow{2}{*}{$\begin{array}{l}\text { Minutes of class time science per week } \\
\text { (popmean: 219.05) }\end{array}$} & $0.051^{* * *}$ & $0.067 * * *$ & $0.066^{* * *}$ \\
\hline & $(0.0083)$ & $(0.0078)$ & $(0.0086)$ \\
\hline School average minutes of reading class & $\begin{array}{l}-\mathbf{0 . 0 1 4} \\
(0.078)\end{array}$ & $\begin{array}{c}\mathbf{0 . 0 3 1} \\
(0.079)\end{array}$ & $\begin{array}{c}\mathbf{0 . 0 8 5} \\
(0.087)\end{array}$ \\
\hline School average minutes of maths class & $\begin{array}{l}-0.095 \\
(0.080)\end{array}$ & $\begin{array}{l}-\mathbf{0 . 0 8 4} \\
(0.081)\end{array}$ & $\begin{array}{c}-\mathbf{0 . 1 2} \\
(0.090)\end{array}$ \\
\hline School average minutes of science class & $\begin{array}{r}\mathbf{0 . 1 5 * * *} \\
(0.045)\end{array}$ & $\begin{array}{l}\text { 0.11** } \\
(0.046)\end{array}$ & $\begin{array}{l}\text { 0.12** } \\
(0.051)\end{array}$ \\
\hline Student ESCS (pop mean: 0.3439) & $\begin{array}{c}9.52 * * * \\
(1.44)\end{array}$ & $\begin{array}{c}11.5 * * * \\
(1.36)\end{array}$ & $\begin{array}{c}11.3^{* * *} \\
(1.49)\end{array}$ \\
\hline School average ESCS (school mean: 0.315) & $\begin{array}{c}\mathbf{6 9 . 8} \mathbf{8}^{* * *} \\
(13.3)\end{array}$ & $\begin{array}{c}72.2 * * * \\
(13.7)\end{array}$ & $\begin{array}{c}78.9 * * * \\
(15.2)\end{array}$ \\
\hline Male interacted with School ESCS & $\begin{array}{c}6.36 \\
(3.91)\end{array}$ & $\begin{array}{l}-0.72 \\
(3.73)\end{array}$ & $\begin{array}{c}2.27 \\
(4.09)\end{array}$ \\
\hline provincial & $\begin{array}{c}2.65 \\
(3.16)\end{array}$ & $\begin{array}{l}\text { 6.96** } \\
(3.28)\end{array}$ & $\begin{array}{c}11.2 * * * \\
(3.63)\end{array}$ \\
\hline remote & $\begin{array}{c}2.06 \\
(7.89)\end{array}$ & $\begin{array}{l}-2.40 \\
(8.14)\end{array}$ & $\begin{array}{c}7.63 \\
(9.01)\end{array}$ \\
\hline More than $40 \%$ of students are ESL & $\begin{array}{c}\mathbf{0 . 8 9} \\
(4.54)\end{array}$ & $\begin{array}{l}8.60 * \\
(4.72)\end{array}$ & $\begin{array}{c}4.71 \\
(5.23)\end{array}$ \\
\hline Computers_per_student pop mean: 0.1729) & $\begin{array}{l}19.0 \\
(12.5)\end{array}$ & $\begin{array}{l}22.8 * \\
(13.0)\end{array}$ & $\begin{array}{c}7.21 \\
(14.4)\end{array}$ \\
\hline Principal thinks shortage of qualified teachers & $\begin{array}{r}5.49 * * \\
(2.62)\end{array}$ & $\begin{array}{l}6.49 * * \\
(2.72)\end{array}$ & $\begin{array}{l}5.31 * \\
(3.02)\end{array}$ \\
\hline Additional instruction for ESL students & $\begin{array}{c}1.12 \\
(2.78)\end{array}$ & $\begin{array}{l}1.18 \\
(2.88)\end{array}$ & $\begin{array}{c}4.94 \\
(3.19)\end{array}$ \\
\hline Preparatory instruction for ESL students & $\begin{array}{c}4.41 \\
(2.85)\end{array}$ & $\begin{array}{c}2.64 \\
(2.96)\end{array}$ & $\begin{array}{c}1.31 \\
(3.28)\end{array}$ \\
\hline Catholic school (reference: government school) & $\begin{array}{l}-3.20 \\
(3.43)\end{array}$ & $\begin{array}{c}-10.1 * * * \\
(3.57)\end{array}$ & $\begin{array}{c}-7.97 * * \\
(3.96)\end{array}$ \\
\hline \multirow[t]{2}{*}{$\begin{array}{l}\text { Independent school (reference: government } \\
\text { school) }\end{array}$} & $-13.7^{* * *}$ & $-21.0 * * *$ & $-14.7^{* * *}$ \\
\hline & $(4.44)$ & $(4.61)$ & (5.11) \\
\hline Student/teacher ratio (pop mean: 13.197) & $\begin{array}{c}\mathbf{0 . 7 1} \\
(0.61)\end{array}$ & $\begin{array}{c}0.42 \\
(0.63)\end{array}$ & $\begin{array}{c}0.57 \\
(0.70)\end{array}$ \\
\hline \multirow{2}{*}{$\begin{array}{l}\text { Constant pressure from parents about academic } \\
\text { performance }\end{array}$} & 4.71 & $6.73^{* *}$ & 2.43 \\
\hline & $(3.02)$ & $(3.15)$ & $(3.49)$ \\
\hline \multirow[t]{2}{*}{$\begin{array}{l}\text { Absenteism hinders students' performance as } \\
\text { stressed by Principal }\end{array}$} & $-12.1^{* * *}$ & $-13.3^{* * *}$ & $-11.2^{* * *}$ \\
\hline & (2.98) & (3.10) & (3.43) \\
\hline School never offers standard tests & $\begin{array}{l}-3.29 \\
(2.72)\end{array}$ & $\begin{array}{l}-3.04 \\
(2.83)\end{array}$ & $\begin{array}{l}-4.49 \\
(3.14)\end{array}$ \\
\hline NSW (reference ACT) & $\begin{array}{c}\text { 26.2** } \\
(10.3)\end{array}$ & $\begin{array}{c}\mathbf{1 6 . 9} \\
(10.7)\end{array}$ & $\begin{array}{c}\text { 23.4** } \\
(11.8)\end{array}$ \\
\hline \multirow[t]{2}{*}{ VIC (reference ACT) } & $42.9 * * *$ & $36.9 * * *$ & $33.4^{* * *}$ \\
\hline & $(10.8)$ & $(11.1)$ & $(12.3)$ \\
\hline \multirow[t]{2}{*}{ QLD (reference ACT) } & $45.1 * * *$ & $45.0 * * *$ & $45.3^{* * *}$ \\
\hline & $(10.4)$ & $(10.8)$ & $(12.0)$ \\
\hline \multirow[t]{2}{*}{ SA (reference ACT) } & $34.6 * * *$ & $35.0 * * *$ & $31.8 * * *$ \\
\hline & $(10.6)$ & $(10.9)$ & $(12.1)$ \\
\hline WA (reference ACT) & $42.6 * * *$ & $44.9 * * *$ & $43.1 * * *$ \\
\hline
\end{tabular}




\begin{tabular}{|c|c|c|c|}
\hline & $(10.9)$ & $(11.2)$ & $(12.5)$ \\
\hline \multirow[t]{2}{*}{ TAS (reference ACT) } & 17.6 & 18.2 & 12.4 \\
\hline & $(10.9)$ & $(11.3)$ & $(12.5)$ \\
\hline \multirow[t]{2}{*}{ NT(reference ACT) } & $23.2 * *$ & $30.2 * * *$ & 16.2 \\
\hline & $(10.1)$ & $(10.5)$ & $(11.6)$ \\
\hline \multirow[t]{2}{*}{ NSW_sescs (interaction state and school escs) } & $-26.7^{*}$ & -16.1 & -23.8 \\
\hline & $(13.8)$ & $(14.3)$ & $(15.8)$ \\
\hline \multirow[t]{2}{*}{ VIC_sescs } & $-41.5 * * *$ & $-37.5^{* *}$ & $-39.4 * *$ \\
\hline & $(14.5)$ & $(15.0)$ & $(16.6)$ \\
\hline \multirow[t]{2}{*}{ QLD_sescs } & $-34.0 * *$ & $-35.0 * *$ & $-43.1 * *$ \\
\hline & $(14.7)$ & $(15.2)$ & (16.9) \\
\hline \multirow[t]{2}{*}{ SA_sescs } & $-37.6 * *$ & $-28.2 *$ & $-38.2 * *$ \\
\hline & $(14.9)$ & $(15.5)$ & $(17.2)$ \\
\hline \multirow[t]{2}{*}{ WA_sescs } & $-40.7 * * *$ & $-29.4^{*}$ & -25.7 \\
\hline & (15.7) & $(16.3)$ & $(18.1)$ \\
\hline \multirow[t]{2}{*}{ TAS_sescs } & -4.24 & -9.40 & -8.18 \\
\hline & $(17.2)$ & $(17.8)$ & $(19.7)$ \\
\hline \multirow[t]{2}{*}{ NT_escs } & 4.35 & -1.18 & 3.55 \\
\hline & $(4.55)$ & $(4.31)$ & $(4.71)$ \\
\hline \multirow[t]{2}{*}{ Constant } & $531 * * *$ & $495 * * *$ & $517 * * *$ \\
\hline & $(14.6)$ & $(15.0)$ & (16.6) \\
\hline \multirow[t]{2}{*}{ var(_cons) } & 280.69 & 334.19 & 414.84 \\
\hline & 35.56 & 38.43 & 46.43 \\
\hline \multirow[t]{2}{*}{ var(residuals) } & 4794.65 & 4279.48 & 5122.23 \\
\hline & 67.7 & 60.43 & 72.29 \\
\hline Observations & 10,396 & 10,396 & 10,396 \\
\hline No of Schools & 348 & 348 & 348 \\
\hline R-squared & 0.477 & 0.438 & 0.443 \\
\hline Variance Partition Coefficient & 0.055 & 0.072 & 0.075 \\
\hline
\end{tabular}

Standard errors in parentheses ** $p<0.01,{ }^{* \star} p<0.05,{ }^{*} p<0.1$ 
Figure A1: Estimated school effects after control for students and schools characteristics, Reading scores (PISA 2009)

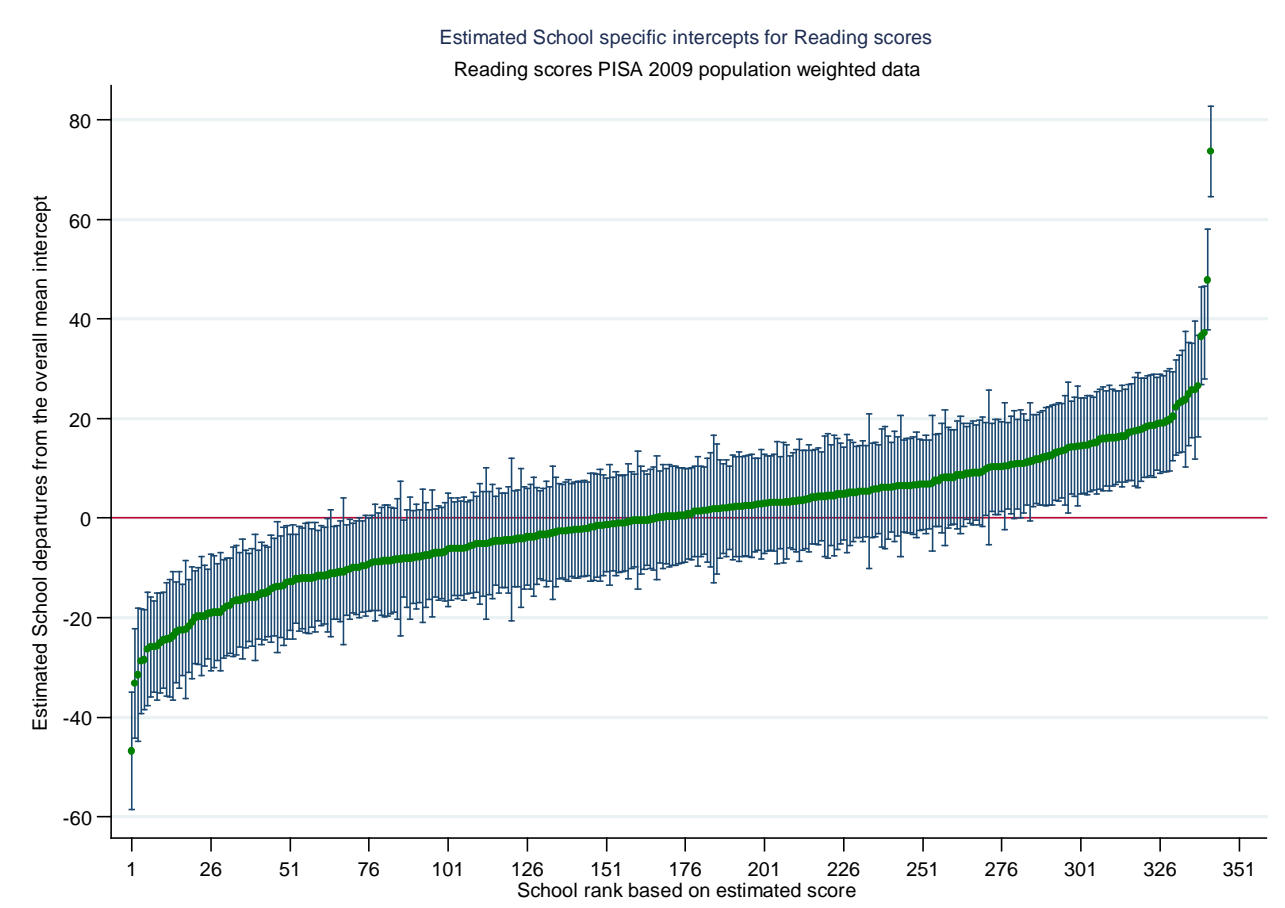

Figure A2: Estimated school effects after control for students and schools characteristics, Maths scores (PISA 2009)

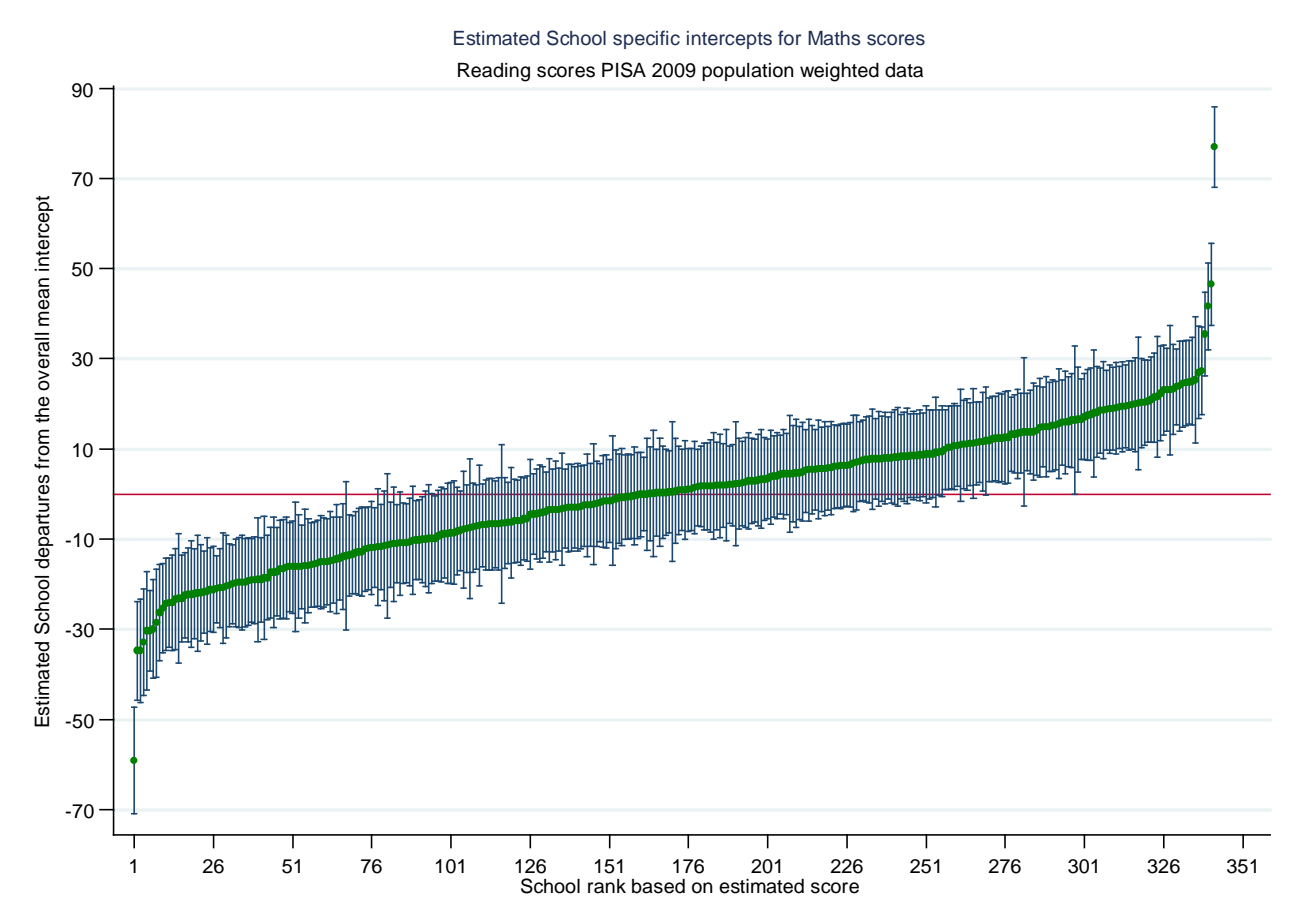


Figure A3: Estimated school effects after control for students and schools characteristics, Science scores (PISA 2009)

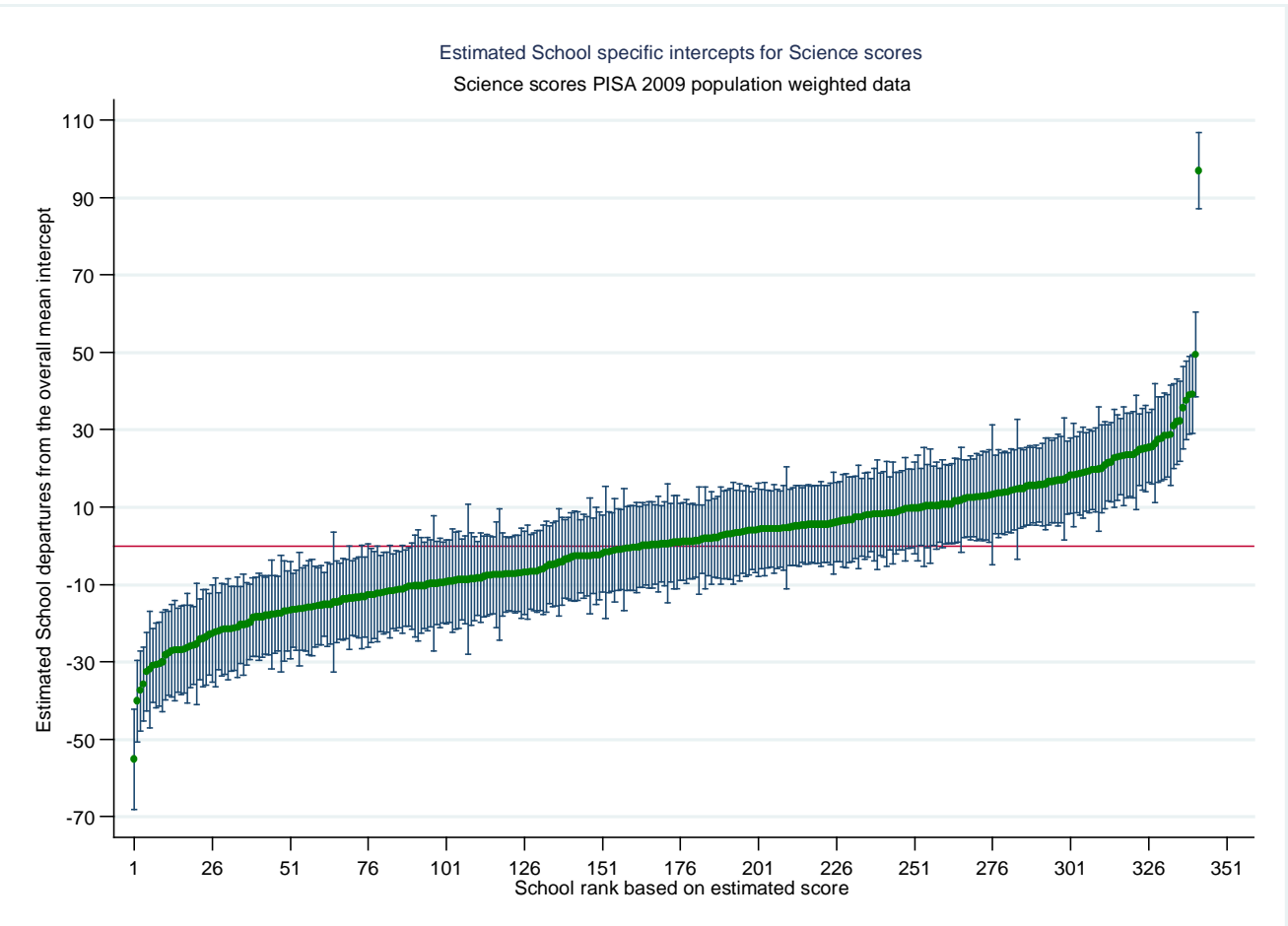




\section{References}

Cardak B.A., Vecci J., (2013), "Catholic school effectiveness in Australia: A reassessment using selection on observed and unobserved variables”, Economics of Education Review, 37, pp. 34-45.

Goldstein, H. 2002. Multilevel Statistical Models. London: Hodder Arnold.

Gonski J. (2011). Review of funding for schooling, Final Report. Canberra: Australian Government.

Hanushek, E. A., \& Rivkin, S. G. 2010. "Generalizations about using value-added measures of teacher quality.”, American Economic Review, 100(2), pp. 267-271.

Lubienski C.A., Lubienski S.T. (2013). Why Public Schools outperform Private Schools. University of Chicago Press, Chicago, USA.

Rabe-Hesketh, S., and A. Skrondal. 2008. Multilevel and Longitudinal Modeling Using Stata. 2nd ed. College Station, TX: Stata Press.

Ryan C., (2013), “What is behind the decline in student achievement in Australia?”, Economics of Education Review, 37, pp.226-239.

Meyer, S. (1997). What Money Can’t Buy: Family Income and Children’s Life Chances. Cambridge: Harvard University Press.

Dearden L., Ferri J., Meghir C., (2002), "The effect of school quality on educational attainment and wages”, Review of Economics and Statistics, vol 84 no1, pp. 1-20. 